\title{
Anti-infection roles of miR-155-5p packaged in exosomes secreted by dendritic cells infected with Toxoplasma gondii
}

\author{
Dan Jiang, Shuizhen Wu, Liqing Xu, Guantai Xie, Dongliang Li and Hongjuan Peng*
}

\begin{abstract}
Background: Toxoplasma gondii is a zoonotic intracellular protozoon that is estimated to infect about $30 \%$ of the world's population, resulting in toxoplasmosis in immunocompromised patients and adverse outcomes in cases of primary infection during pregnancy. Exosomes are tubular vesicles secreted by cells, and function in intercellular communication. It has been reported that the exosomes secreted by T. gondii-infected immune cells transmit infection signals to the uninfected cells. However, the mechanism and effect of the exosome transmission are still vague. We therefore investigated the function of the exosomes transmitted from DC2.4 cells infected with the T. gondii RH strain ( $T g$-DC-Exo) to the uninfected cells, as well as their roles in anti-infection.
\end{abstract}

Methods: We conducted exosome isolation and identification with ultracentrifugation, transmission electron microscopy (TEM), nanoparticle tracking analysis (NTA), and western blot (WB) analysis. Exosome uptake by recipient cells was identified by PKH67 assay. The signal transmission and the abundance of miR-155-5p were determined using transwell assay and qRT-PCR. For detection of immune responses, cytokine secretion was evaluated. The T. gondii B1 gene was determined to evaluate tachyzoite proliferation.

Results: We observed that Toxoplasma infection upregulated miR-155-5p expression in DC2.4 cell-secreted exosomes, and those exosomes could be ingested by murine macrophage RAW264.7 cells. Tg-DC-Exo and miR$155-5 p$ stimulated host proinflammatory immune responses including increased production of proinflammatory cytokines IL-6 and TNF-a, and proinflammatory marker-inducible nitric oxide synthase (iNOS). The NF-kB pathway was activated by downregulation of SOCS1, leading to inhibition of T. gondii tachyzoite proliferation in RAW264.7 cells.

Conclusions: Our findings provide a novel mechanism for how infected cells transmit infection signals to the uninfected cells through exosome secretion after T. gondii infection, followed by inflammatory responses and antiinfection reactions, which may help us develop a new strategy for toxoplasmosis prevention, especially in immunocompromised patients.

Keywords: Toxoplasma gondii, Exosomes, RAW264.7 cells, miR-155-5p, SOCS1

${ }^{*}$ Correspondence: floriapeng@hotmail.com

Department of Pathogen Biology, Guangdong Provincial Key Laboratory of Tropical Disease Research, School of Public Health, Southern Medical University, Guangzhou 510515, Guangdong Province, China

\begin{abstract}
Background
Toxoplasma gondii is an obligate intracellular protozoon that infects almost one third of the world's population [1]. The infection is usually asymptomatic, but poses a lifelong threat to immunocompetent populations; however, it may result in severe toxoplasmosis and even death in immunocompromised patients, and primary infection during pregnancy may result in adverse pregnancy
\end{abstract} original author(s) and the source, provide a link to the Creative Commons licence, and indicate if changes were made. The images or other third party material in this article are included in the article's Creative Commons licence, unless indicated otherwise in a credit line to the material. If material is not included in the article's Creative Commons licence and your intended use is not permitted by statutory regulation or exceeds the permitted use, you will need to obtain permission directly from the copyright holder. To view a copy of this licence, visit http://creativecommons.org/licenses/by/4.0/. The Creative Commons Public Domain Dedication waiver (http://creativeco mmons.org/publicdomain/zero/1.0/) applies to the data made available in this article, unless otherwise stated in a credit line to the data. 
outcomes [1]. Host immune responses mediate the effects of T. gondii infection [2]. For example, interferongamma (IFN- $\gamma$ ), interleukin-12 (IL-12), and IL-1 $\alpha$ have been reported to promote protective immunity against T. gondii infection [3-5]. Macrophages are important components of the innate immune system; they scavenge pathogens by activating innate immunity or promoting adaptive immunity through antigen presentation [6]. Many T. gondii secretions, including ROP16, GRA12, GRA15, and GRA2, have been reported to regulate the host immune response [7-9].

Exosomes are $30-200 \mathrm{~nm}$ extracellular vesicles enriched in proteins, nucleic acids, glycoconjugates, lipids, and other biological substances, which are powerful tools for intercellular communication that mediate biological, physiological, and pathological states related to immune responses $[10,11]$. Most cells and pathogens can secrete exosomes containing unique surface molecules and contents including proteins, microRNAs (miRNAs), and messenger RNAs (mRNAs), which participate in host pathogenesis [12, 13]. It has been reported that $T$. gondii exosomes can trigger humoral and cellular immune responses and promote the secretion of proinflammatory cytokines by macrophages [14, 15]. Toxoplasma gondii exosome immunization was found to be capable of inducing immune protection to prolong mice survival $[16,17]$. Nematode exosomes can inhibit the innate type 2 response [18]. Schistosoma mansoni exosomes contain schistosome-derived miRNAs and proteins involved in host-parasite interactions [19]. It has been shown that exosomes have potential for use in vaccine development and therapeutic innovation $[20,21]$.

Small non-coding RNAs, or microRNAs (miRNAs), inhibit the transcription and translation of the target genes, mainly by binding to the $3^{\prime}$-UTR regions. Exosomes released by immune cells can carry miRNAs from donor cells to recipient cells to regulate biological processes [22]. Rather than regulating their own cells, exosomal miRNAs can regulate proximal and distal target cells through exosome transportation or other means. However, how exosomal miRNA works has not been fully characterized. Several highly expressed miRNAs have been identified from the extracellular vesicles of Schistosoma japonicum and have been found to be able to suppress target gene expression in RAW264.7 cells [23].

The activation of $\mathrm{CD}^{+} \mathrm{T}$ cells is essential for inhibition of T. gondii infection [24]. Dendritic cells and macrophages are important antigen-presenting cells for $\mathrm{T}$ cells, which play important roles in anti-infection [25, 26]. The communication between these immune cells is particularly important. However, the exact mechanism by which the exosomes secreted by dendritic cells transmit the anti-infection signals to macrophages is not totally established. This study was conducted to answer this question.

\section{Methods \\ Parasites and cell lines}

Murine dendritic cell line DC2.4, human foreskin fibroblast (HFF) cell line, and murine macrophage cell line RAW264.7 were purchased from the American Type Culture Collection (ATCC, Manassas, VA, USA) and preserved in our laboratory. The DC2.4 cells were cultured in RPMI-1640 (Roswell Park Memorial Institute-1640; Gibco/Invitrogen, Waltham, MA, USA); HFF and RAW264.7 cells were cultured in Dulbecco's modified Eagle's medium (DMEM) (Gibco/Invitrogen). Both of the culture mediums were supplemented with $10 \%$ fetal bovine serum (FBS) (Gibco/Invitrogen) and 1\% gentamicin (10 mg/ml, Invitrogen, USA). The cells were cultured with $5 \% \mathrm{CO}_{2}$ at $37{ }^{\circ} \mathrm{C}$. The Toxoplasma gondii $\mathrm{RH}$ strain was propagated in HFF cells in our laboratory.

\section{Exosome isolation}

DC2.4 cells were cultured with RPMI-1640 complete medium supplemented with $10 \%$ exosome-free FBS (Gibco) in eight $75 \mathrm{~cm}^{2}$ cell culture flasks to $90-100 \%$ confluence; four flasks were infected with RH tachyzoites at a multiplicity of infection (MOI) of 3 for $0.5 \mathrm{~h}$, and the unrecruited tachyzoites were washed off three times with PBS. After that, the eight flasks were cultured with the exosome-free RPMI-1640 complete medium for $28 \mathrm{~h}$. The supernatants were centrifuged at $2000 \times g$ at $4{ }^{\circ} \mathrm{C}$ for $30 \mathrm{~min}$ to remove cells and cell debris, followed by centrifugation at $10,000 \times g$ at $4{ }^{\circ} \mathrm{C}$ for $45 \mathrm{~min}$ to remove insoluble particles, and then ultracentrifugation at $100,000 \times g$ at $4{ }^{\circ} \mathrm{C}$ for $120 \mathrm{~min}$ to harvest the exosomes. Ultracentrifugation was repeated once, and the supernatant was carefully aspirated. The precipitates were resuspended in $200 \mu \mathrm{lBS}$ and stored at $-80^{\circ} \mathrm{C}$ for use [27].

\section{Exosome identification}

Isolated exosomes were examined using transmission electron microscopy (TEM) (Hitachi, Tokyo, Japan) at a voltage of $80 \mathrm{kV}$. Exosomal proteins were detected with western blotting (WB) [27], and the exosome size was determined using a ZetaView ${ }^{\circledR}$ nanoparticle tracker (Particle Metrix, Germany) as described previously [28]. The ZetaView combines classic microelectrophoresis techniques with Brownian motion to provide information about particle size, zeta potential, and particle concentration. Briefly, the ZetaView sample cubicle was washed with distilled water and slowly injected with exosome diluent samples. The size of the exosomes was measured. Exosomal total protein concentration was determined using a Pierce BCA Protein Assay Kit (Thermo Fisher 
Scientific, MA, USA) according to the manufacturer's instructions.

\section{Western blot}

The isolated exosomes and the transfected cells were collected and lysed using lysis buffer (Beyotime Biotechnology, Shanghai, China), total proteins were loaded for sodium dodecyl sulphate-polyacrylamide gel electrophoresis (SDS-PAGE), and WB was performed as described previously [29]. The following primary antibodies were used: CD9 rabbit monoclonal antibody (mAb; 1:1000), TSG101 rabbit mAb (1:1000), HSP70 rabbit mAb (1:1000), iNOS rabbit mAb (1:1000), p65 rabbit mAb (1:1000), and SOCS1 rabbit mAb (1:1000) purchased from Abcam (MA, USA); GAPDH mouse mAb (1:1000), phosphorylated ІкB alpha (Ser32/Ser36) mouse mAb (1:1000), and phosphorylated NF-kB p65 (S536) mouse mAb (1:1000) purchased from Affinity Biosciences $(\mathrm{OH}$, USA); and IKB $\alpha$ rabbit $m A b$ (1:1000) purchased from GeneTex (Santa Cruz, CA, USA). The secondary antibodies used for WB were horseradish peroxidase (HRP)-conjugated goat anti-mouse immunoglobulin G (IgG; 1:5000) and HRP goat anti-rabbit IgG (1:5000) purchased from ABclonal (Wuhan, China).

\section{Detection of uptake of $T g$-DC-exo and DC-exo by RAW264.7 cells}

RAW264.7 cells were seeded on coverslips in a 12-well plate, at approximately $1.1 \times 10^{6}$ cells per well, and were cultured with DMEM supplemented with $10 \%$ exosomefree FBS for $12 \mathrm{~h}$. Exosomes extracted from the supernatants of $T$. gondii-infected DC2.4 cells ( $T g$-DC-Exo) and DC2.4 cells (DC-Exo) were labeled with green fluorescence using a PKH67 Green Fluorescent Cell Linker Mini Kit (Sigma-Aldrich, USA) according to the experimental procedures described by Lin et al. [30]. Briefly, $\mathrm{Tg}$-DC-Exo and DC-Exo ( $5 \mu \mathrm{g}$ for each) were respectively mixed in $40 \mu \mathrm{l}$ of PBS with $50 \mu \mathrm{l}$ Diluent $\mathrm{C}$ and $0.25 \mu \mathrm{l}$ PKH67 dye, mixed gently for $5 \mathrm{~min}$ at room temperature, and $1 \%$ bovine serum albumin (BSA) was added to terminate the dying process. PKH67-stained $T g$-DC-Exo and DC-Exo were recollected at $100,000 \times g$ for $2 \mathrm{~h}$ at $4{ }^{\circ} \mathrm{C}$ and resuspended in PBS. PKH67-stained exosomes or the same volume of the PKH67-PBS control were separately added to the RAW264.7 cells and incubated for $6 \mathrm{~h}$. The cells were washed three times with PBS times and fixed in $4 \%$ paraformaldehyde for $10 \mathrm{~min}$ (Dingguo, China). The coverslips were taken out, rinsed with double-distilled water, and air-dried. The coverslips were mounted with DAPI Fluoromount ${ }^{\circledR}$ (Southern Biotech, USA) and then observed under a fluorescence microscope (Nikon, Tokyo, Japan) with a green fluorescence protein (GFP) filter, and images were captured at $\times 1000$ magnification.

\section{RNA and DNA isolation and Quantitative Reverse} Transcription-Polymerase Chain Reaction (qRT-PCR)

The total RNA of exosomes was extracted with an exoRNeasy Serum/Plasma Midi Kit (QIAGEN, Duesseldorf, Germany) according to the manufacturer's protocol. The total RNA of cells was extracted with TRIzol reagent (Thermo Fisher Scientific, Waltham, MA, USA) according to the manufacturer's protocol. Genomic DNA was removed with a One-Step gDNA Removal Kit (Trans Gen Biotech, Beijing, China). For miRNA analysis, exosomal RNA was reverse-transcribed using SuperScript ${ }^{\mathrm{TM}}$ II reverse transcriptase (Thermo Fisher Scientific, Wilmington, DE, USA), and cell RNA was reverse-transcribed using EasyScript ${ }^{\circledR}$ All-in-One First-Strand cDNA Synthesis SuperMix. To evaluate the relative amount of T. gondii tachyzoites, the total DNA of infected cells was extracted with a DNeasy Blood and Tissue Kit, and Proteinase K (QIAGEN, Duesseldorf, Germany) was used according to the manufacturer's protocol. Detection of the T. gondii B1 gene was carried out following previously reported procedures [31]. Real-time polymerase chain reaction (PCR) was performed using the Hieff ${ }^{\circledR}$ qPCR SYBR ${ }^{\circledR}$ Green Master Mix (Yeasen, Shanghai, China) and the QuantStudio $^{\mathrm{TM}}$ real-time PCR system (Thermo Fisher Scientific, Wilmington, DE, USA). The primers for quantitative PCR (qPCR) are shown in Additional file 1: Table S1. The relative mRNA level was measured using the $2^{-\Delta \Delta \mathrm{Ct}}$ method.

\section{Detection of macrophage polarization after treatment of RAW264.7 cells with $\mathrm{Tg}$-DC-exo and DC-exo}

RAW264.7 cells were cultured with DMEM supplemented with $10 \%$ exosome-free FBS in 24-well plates to 60-80\% confluence, and $\mathrm{Tg}$-DC-Exo or DC-Exo were added to a final concentration of $120 \mu \mathrm{g} / \mathrm{ml}$. The cells were cultured for $24 \mathrm{~h}$ for total RNA isolation, and $48 \mathrm{~h}$ for total protein extraction. The total RNA isolation, complementary (cDNA) preparation, and qPCR were performed as described above. With the total protein, the proinflammatory marker (iNOS) was detected with WB.

\section{Transwell experiment}

DC2.4 cells were seeded in the upper chambers of 24-well transwell inserts (Corning, NY, USA) and cultured with DMEM supplemented with $10 \%$ exosome-free FBS and $1 \%$ gentamicin to $100 \%$ confluence. The cells were divided into four groups: two groups were left uninfected, and two groups were infected with the $T$. gondii $\mathrm{RH}$ strain at MOI of 3. After infection for $30 \mathrm{~min}$, the culture medium was aspirated, and the DC2.4 cells in the upper chambers were washed three times with PBS to remove the unrecruited T. gondii tachyzoites. Meanwhile, RAW264.7 cells were seeded in the lower chambers. The four groups of 
DC2.4 cells (two infected with T. gondii and two uninfected) in the upper chambers and the RAW264.7 cells in the lower chambers were co-cultured in DMEM supplemented with $10 \%$ exosome-free FBS and $1 \%$ gentamicin, with or without $100 \mu \mathrm{l}$ of $10 \mu \mathrm{m} \mathrm{GW4869}$ (inhibitor of exosome secretion, MedChemExpress, USA) for $52 \mathrm{~h}$. These groups were labeled as normal, DC2.4+GW4869, $\mathrm{DC} 2.4+\mathrm{RH}$, and $\mathrm{DC} 2.4+\mathrm{RH}+\mathrm{GW} 4869$. Next, the RAW264.7 cells were harvested and lysed with lysis buffer (Beyotime Biotechnology, China). The total RNAs were extracted for detection of miR-155-5p abundance via quantitative real-time PCR (qRT-PCR). Each group was prepared in triplicate, and the experiment was carried out three times for statistical analysis.

\section{Cell transfection with synthesized miRNA or siRNA and treatment with exosomes}

RAW264.7 cells were seeded in 6-well plates to 60-80\% confluence and divided into four groups. Two groups were transfected with $10 \mu \mathrm{l}$ of $20 \mathrm{~nm}$ miR-155-5p mimics and mimic-normal control (miRNA mimic-NC), and miR-155-5p inhibitors and miRNA inhibitor-normal control (miRNA inhibitor-NC) (Gene Pharma, Suzhou, China), respectively. The other two groups were transfected with $10 \mu \mathrm{l}$ of $20 \mathrm{~nm}$ si-socs 1 (siRNA targeting socs1) and si-NC (siRNA-NC) (RiboBio, Guangzhou, China), respectively. The transfection was performed using Lipofectamine 3000 (Thermo Fisher Scientific) according to the protocol provided by the manufacturer. The exosomes extracted from the cell culture supernatant of the DC2.4 (DC-Exo) and the DC2.4 infected with $T$. gondii (Tg-DC-Exo) were added to the $60-80 \%$ confluent RAW264.7 cells at $120 \mu \mathrm{g} /$ well, respectively.

\section{Cell activity, proliferation, and polarization detection}

The RAW264.7 cells were incubated with exosomes or transfected with miRNA/siRNA. At $24 \mathrm{~h}$ post-treatment, the transcription of the related cytokines was detected via qRT-PCR and WB, and a CCK8 kit (Cell Counting Kit-8, TransGen Biotech, Beijing, China) was used to detect the cell viability and proliferation according to the instructions. Similarly, cell proliferation activity was evaluated by detecting cell absorbance after treatment for $0,24,48,72$, and $96 \mathrm{~h}$. Each group was prepared in triplicate, and the experiment was carried out three times for statistical analysis.

\section{Statistical analysis}

The differences between two or three groups were analyzed with Prism (GraphPad Software) using the Student's $t$-test and one-way analysis of variance (ANOVA). SPSS software (version 20) was used to analyze multiple comparisons (Tukey's test), and $P<0.05$ indicated that the difference was statistically significant.

\section{Results}

Characterization of the exosomes derived from DC2.4 Cells infected or uninfected with $T$. gondii RH strain

The exosomes extracted from the DC2.4 cells infected or uninfected with $T$. gondii presented a specific saucer structure when observed by transmission electron microscopy (TEM) (Fig. 1a). The nanoparticle tracking analysis showed that the particles had a diameter of 30-200 nm, and also revealed particle concentrations of $\mathrm{Tg}$-DC-Exo $\left(5.9 \times 10^{7} \mathrm{particles} / \mathrm{ml}\right)$ and DC-Exo $\left(3.3 \times 10^{7}\right.$ particles $\left./ \mathrm{ml}\right)$ (Fig. 1b, c). Several specific exosome marker proteins, including TSG101, CD9, CD81, and HSP70, were detected in the same volume of exosome extracts with WB (Fig. 1d).

\section{Macrophage (RAW264.7) uptake of exosomes secreted by DC2.4 cells}

To determine whether immune cells can communicate with each other through exosome transmission, we labeled exosomes with PKH67 and incubated them with RAW264.7 for $6 \mathrm{~h}$ in vitro. As the confocal microscope results show (Fig. 2), the RAW264.7 cells successfully engulfed the exosomes (including $T g$-DC-Exo and DCExo) extracted from DC2.4 cells; however, this uptake phenomenon was not observed in the PKH67-PBS and PBS groups.

\section{$\mathrm{Tg}$-DC-exo results in polarization of macrophages toward M1 and promotion of inflammation progress}

Based on the observation that RAW264.7 cells ingested exosomes secreted by DC2.4 cells, we proposed that exosomes were involved in the intercellular communication between different types of immune cells. To test this hypothesis, we treated RAW264.7 cells with Tg-DC-Exo or DC-Exo for $24 \mathrm{~h}$, and then investigated the transcription levels of the proinflammatory cytokines (TNF- $\alpha$, IL-6) and proinflammatory marker iNOS relative to which of the housekeeping gene-glyceraldehyde-3-phosphate dehydrogenase (GAPDH) were detected with realtime PCR. The results showed that the transcription levels of IL-6 $\left(F_{(2,6)}=4043, P<0.0001\right)$, iNOS $\left(F_{(2,6)}=113.5, P<0.0001\right)$, and TNF- $\alpha\left(F_{(2,6)}=53.91\right.$, $P<0.0001)$ were increased in the RAW264.7 cells treated with $\mathrm{Tg}$-DC-Exo compared with those of the cells treated with DC-Exo (Fig. 3a). Consistent with the RT-PCR results, in our WB detection, $T g$-DC-Exo promoted iNOS translation compared with DC-Exo treatment and nontreatment (Fig. $3 \mathrm{~b})\left(F_{(2,6)}=83.47, P\right.$ $<0.0001)$. Taken together, these results indicated that Tg-DC-Exo could induce RAW264.7 M1 macrophage polarization in vitro. 
a

1:Tg-DC-Exo
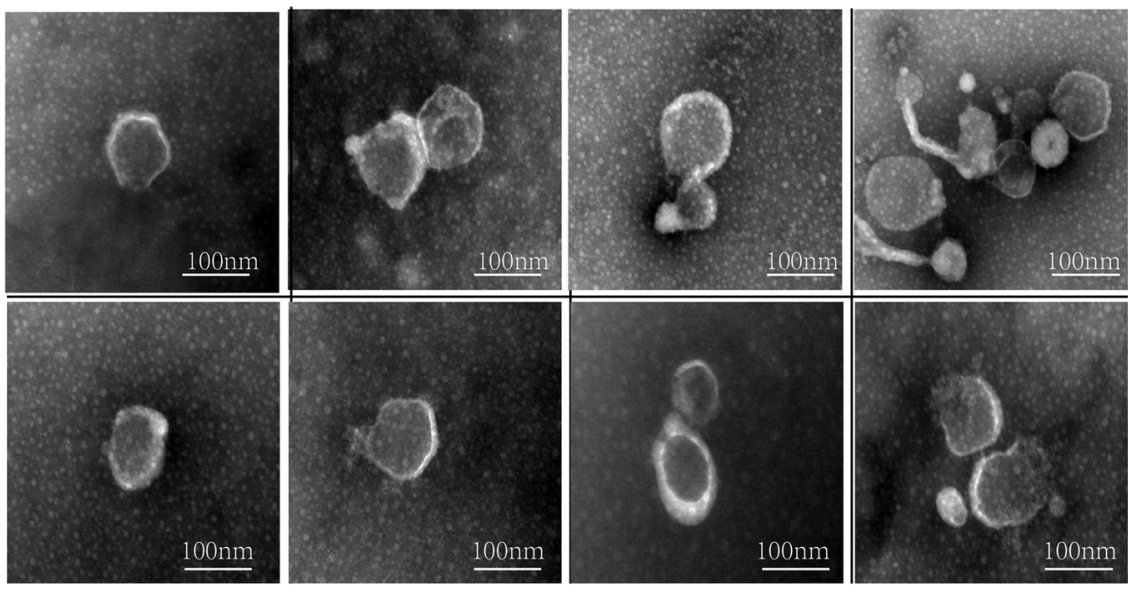

b

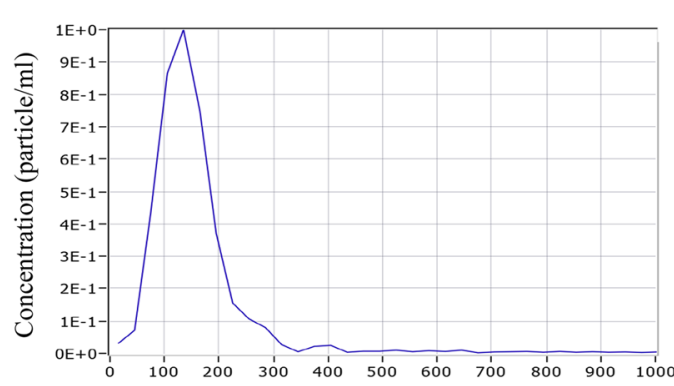

d
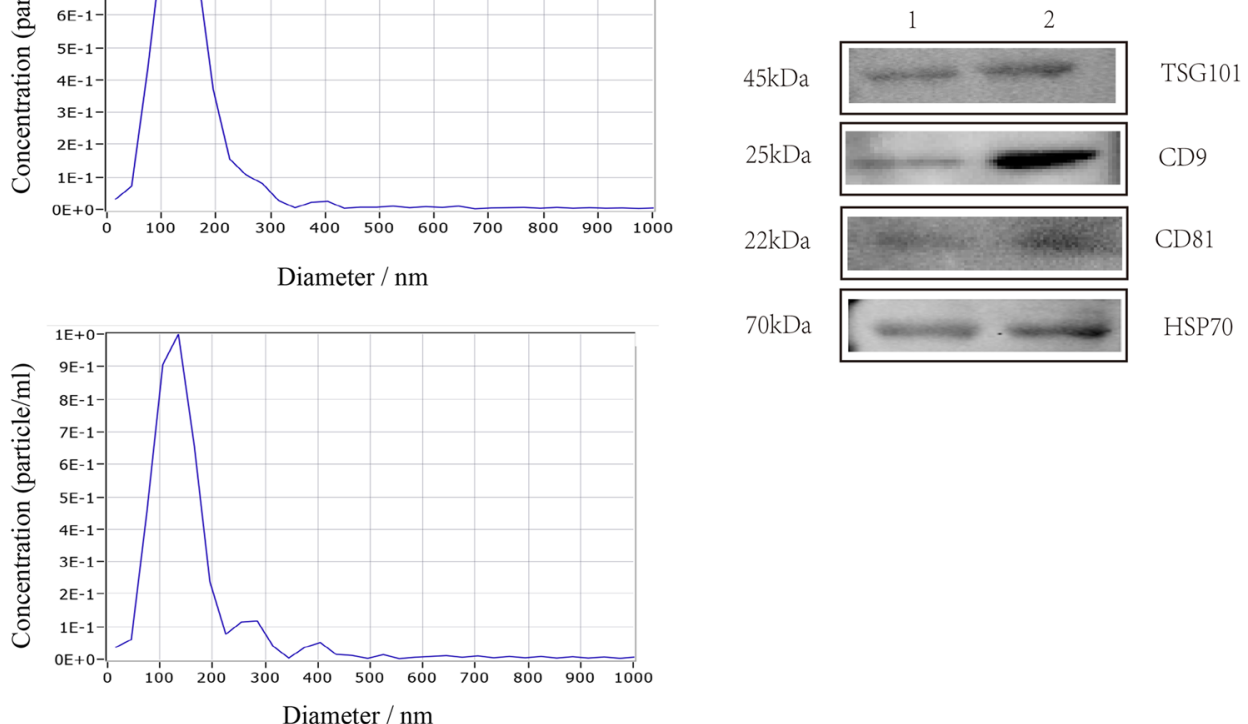

Fig. 1 Identification of the extracted exosomes. Exosomes were extracted from dendritic cells infected with T. gondii (RH strain) for $28 \mathrm{~h}$ or uninfected cells. a Transmission electron microscopy was used to analyze the morphological structure of the exosomes obtained from the infected (Tg-DC-Exo) or uninfected dendritic cells (DC-Exo). Particle size and concentration of Tg-DC-Exo (b) and DC-Exo (c) were detected with nanoparticle tracking analysis (NTA). $\mathbf{d}$ Exosome-specific proteins TSG101, CD9, and CD81 and heat-shock protein HSP70 were detected in DC-Exo (1) or Tg-DC-Exo (2) using western blot

\section{MiR-155-5p is abundantly packed in $T g$-DC-exo} and delivered to recipient cells via exosomes

To examine the potential regulatory roles of dendritic cell exosomes taken up by recipient cells, we identified 19 differentially enriched exosomal miRNAs from the DC2.4 cells infected with T. gondii RH tachyzoites using RNA-seq [27]. To gain further insight into the potential regulatory roles of $\mathrm{Tg}$-DC-Exo miRNA cargo in recipient cells, we selected the abundant miR-155-5p for further analysis. We first confirmed the transcriptome sequencing result of the upregulated miR-155-5p expression in the $\mathrm{Tg}$-DC-Exo group compared with that in the DC-Exo group with qRT-PCR (Fig. 4a) $\left(F={ }_{(2,6)} 777_{(2,6)}=113.5\right.$, $\left.P<0.0001)=\mathrm{t}_{(3)}=6.733, P=0.0067\right)$. To determine whether miR-155-5p could be transported to the recipient cells through the exosomes secreted by the DC 2.4 


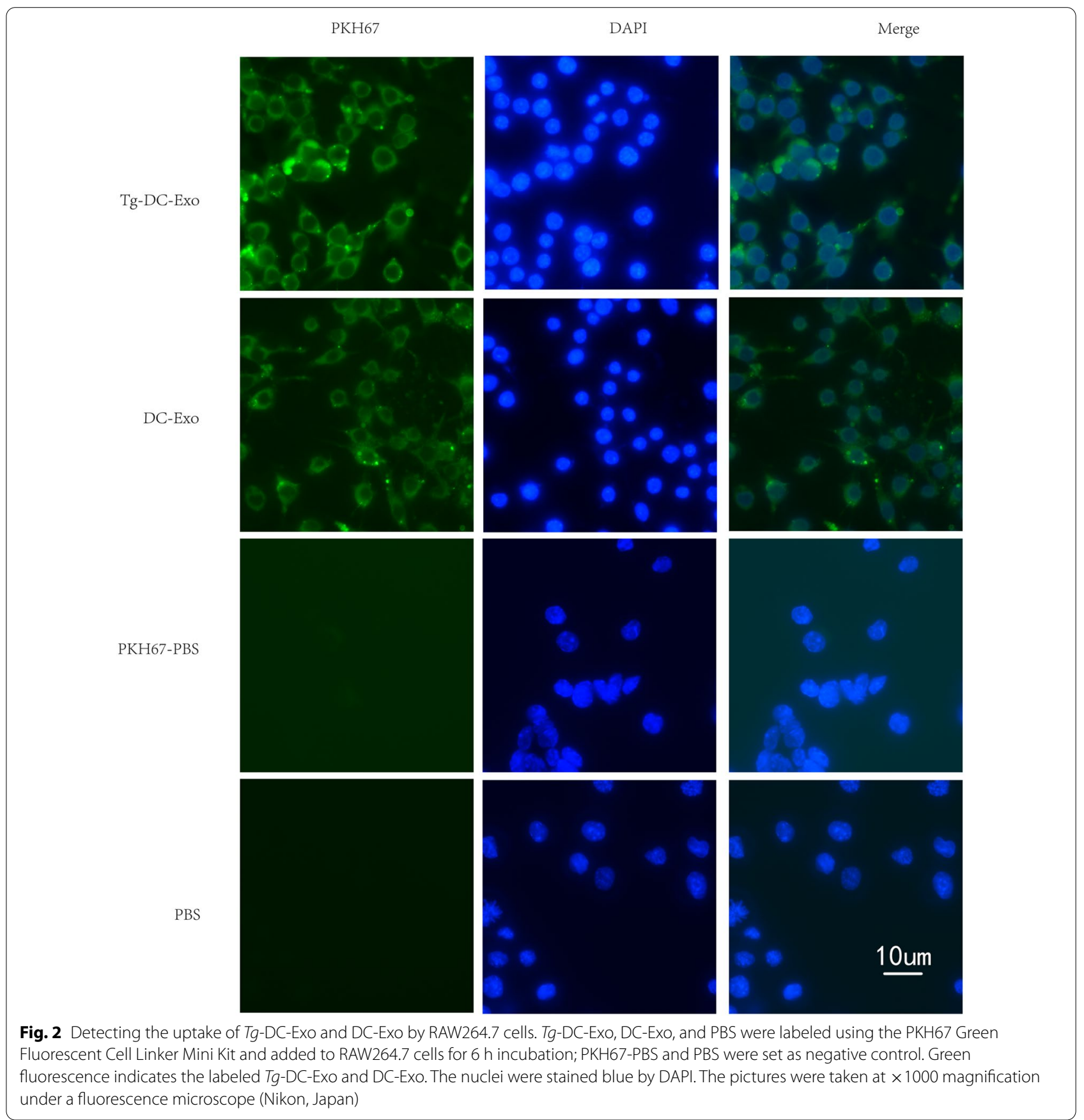

cells infected with T. gondii, RAW264.7 cells were cocultured with $\mathrm{Tg}$-DC-Exo or DC-Exo for $24 \mathrm{~h}$, and the abundance of miR-155-5p was detected with qRT-PCR. The level of miR-155-5p relative to U6 increased by several times in $\mathrm{Tg}$-DC-Exo-treated RAW264.7 cells compared with that in DC-Exo-treated RAW264.7 cells (Fig. 4b) $\left(F_{(2,6)}=46.06, P=0.0002\right)$.

In our transwell experiment, DC2.4 cells infected with T. gondii and uninfected DC2.4 cells were pretreated with GW4869 (an inhibitor of exosome secretion) for $24 \mathrm{~h}$ to prevent the production of exosomes, or were left untreated with GW4869 as a control. Next, RAW264.7 cells were cultured in the lower chambers for $28 \mathrm{~h}$ and then harvested for detection of miR-155-5p transcription with qRT-PCR. We found that the relative transcription level of miR-155-5p in the RAW264.7 cells was significantly reduced in the DC2.4+ $\mathrm{RH}+\mathrm{GW} 4869$ treatment group compared with that in the $\mathrm{DC}+\mathrm{RH}$ treatment 


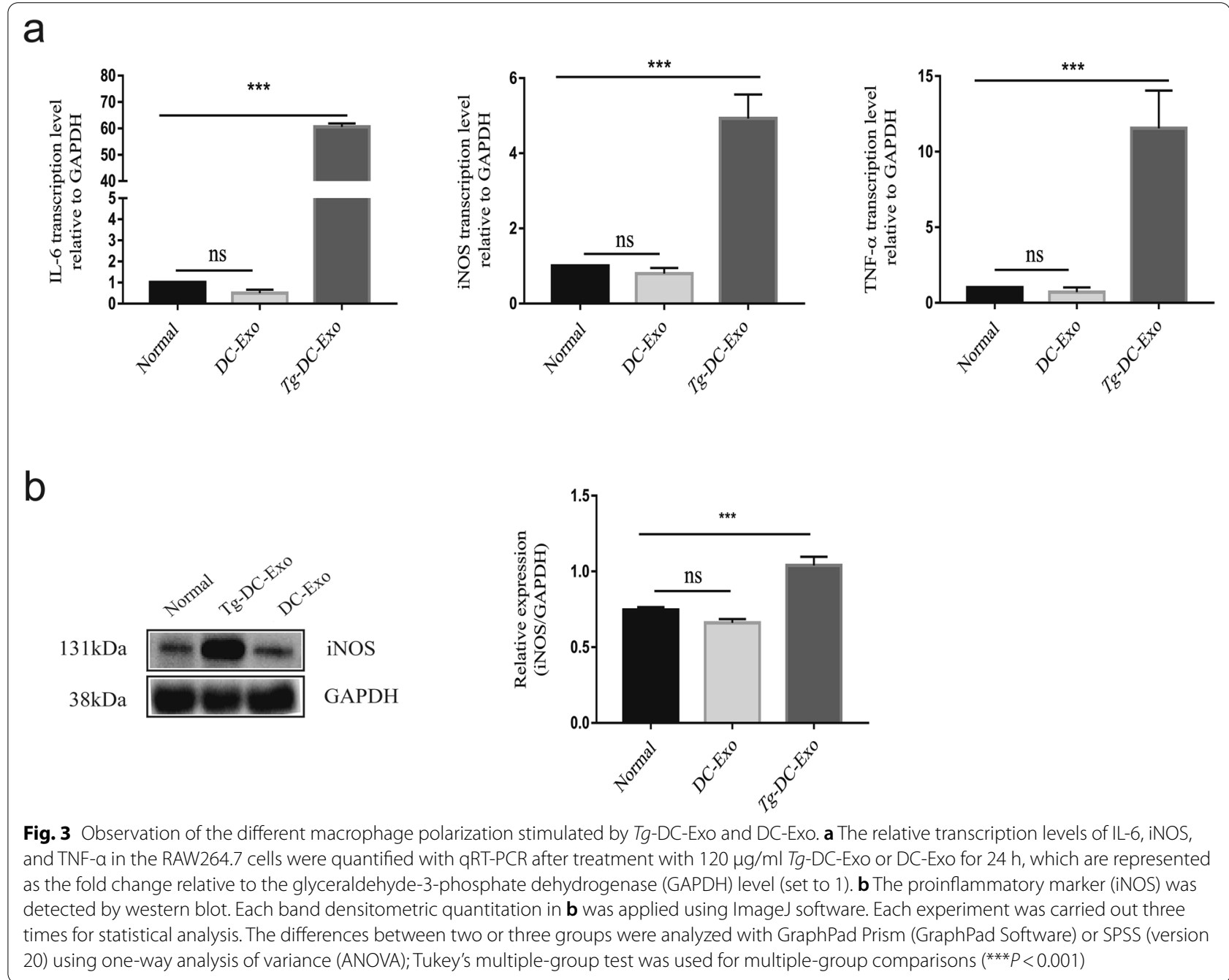

group (Fig. $4 \mathrm{c})\left(F_{(3,16)}=47.01, P<0.0001\right)$. All these data indicated that the miR-155-5p enriched in the exosomes derived from DC2.4 cells infected with T. gondii was transported to and absorbed in the RAW264.7 cells.

The miR-155-5p packed in the exosomes secreted by DC2.4 cells infected with $T$. gondii ( $T g$-DC-exo) modulates macrophage polarization

In this study, we found that miR-155-5p was highly enriched in $T g$-DC-Exo $\left(t_{(3)}=6.733, P=0.0067\right)$ and $\mathrm{Tg}$-DC-Exo-induced RAW264.7 M1 polarization $(P<0.0001)$. We therefore hypothesized that miR-155-5p could be a key factor that plays an important role in $T g$ DC-Exo-induced M1 polarization of RAW264.7. We first transfected miR-155-5p mimics and miR-155-5p inhibitors into RAW264.7 cells and miR-155-5p inhibitors into DC2.4 cells, and consistent levels of miR-155-5p were detected in the transfected RAW264.7 cells with
qRT-PCR (Additional file 2: Figure S1a) $(P=0.011)$. Proliferation of these RAW264.7 cells was detected with a CCK8 kit at different times post-transfection. However, no significant differences were found in cell proliferation and viability at different time points among these transfected or un-transfected RAW264.7 cells (Additional file 2: Figure $\mathrm{S} 1 \mathrm{~b})\left(F_{(2,6)}=28.4, P=0.0001\right)$. We further speculated that miR-155-5p modulated the polarization direction of macrophages. We found in our experiments that miR-155-5p mimics led to significant upregulated transcription levels of proinflammatory cytokines IL-6 $\left(F_{(3,8)}=533.4, P=0.0246\right)$ and TNF- $\alpha\left(F_{(3,8}\right)=61.5, P$ $=0.0022)$ and proinflammatory marker (iNOS) $\left(F_{(3,8)}=\right.$ 49.2, $P=0.0002)$ in RAW264.7 cells compared to that in miRNA mimic-NC and mock treatment cells (Fig. 5a). To further verify the role of miR-155-5p in macrophages, we transfected a miR-155-5p inhibitor to DC2.4 and then extracted the exosomes (miR-155-5p inhibitor-DC-Exo). 

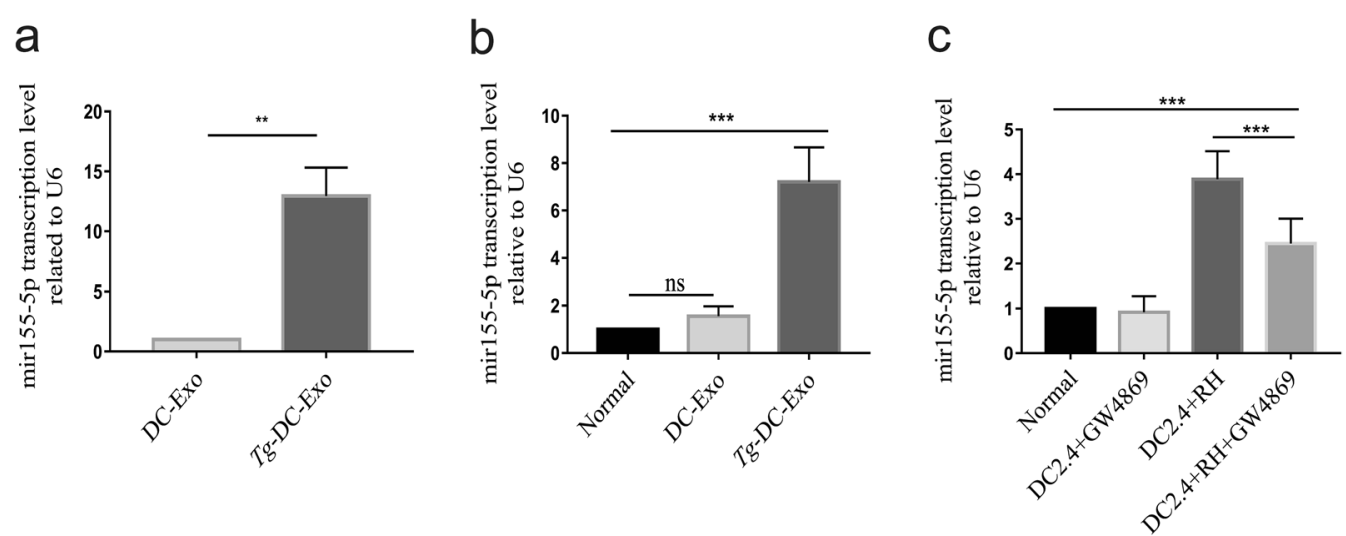

Fig. 4 Evidence of miR-155-5p being enriched in Tg-DC-Exo and delivered to recipient cells via exosomes. a qRT-PCR confirmation of the abundance of miR-155-5p in Tg-DC-Exo and DC-Exo. b After RAW264.7 cells were treated with $120 \mathrm{\mu g} / \mathrm{ml}$ Tg-DC-Exo or DC-Exo for $24 \mathrm{~h}$, the miR-155-5p transcription levels were quantified with qRT-PCR and represented as the fold change relative to the U6 level (set to 1); normal cells were set as the negative control. c DC2.4 cells were pre-cultured in upper transwell chambers overnight. As indicated, the DC2.4 cells were pretreated with GW4869 or not treated, followed by infection with RH tachyzoites for 30 min or non-infection, and then the unrecruited tachyzoites were washed off. Synchronously, RAW264.7 cells were cultured in the lower chambers together with the infected DC2.4 cells in the upper chambers, in the same well for $28 \mathrm{~h}$. The miR-155-5p transcription levels in each lower chamber were detected with qRT-PCR, and represented as the fold change relative to the U6 level (set to 1); normal cells were set as the negative control. Data are presented as mean \pm standard deviation (SD). Student's t-test and one-way ANOVA were used for the significance analysis, and Tukey's multiple-group test was used for multiple-group comparisons. Each experiment was carried out three times for statistical analysis. $\left({ }^{* *} P<0.01\right.$ and $\left.{ }^{* * *} P<0.001\right)$

The miR-155-5p inhibitor-DC-Exo and the exosomes extracted from the normal DC2.4 cells (negative controlExo) were added to RAW264.7 cells and incubated for $24 \mathrm{~h}$, after which the cytokines in the culture medium were detected. However, no significant differences in cytokine levels were found between these groups (Additional file 3: Figure S2). Considering the low background level of miR-155-5p [32] and loss of exosomes in extraction, the inhibition effect of the miR-155-5p in exosomes may be unobservable. Therefore, we further transfected a miR-155-5p inhibitor to RAW264.7 cells and found it significantly inhibited the transcription of IL-6, iNOS, and TNF- $\alpha$ in RAW264.7 cells compared to that in miRNA-NC inhibitor (miRNA normal control inhibitor) treatment and mock treatment groups (Fig. $5 \mathrm{~b})(P=$ $0.001)$. WB showed a result consistent with that of the qRT-PCR: miR-155-5p mimics significantly upregulated iNOS expression in RAW264.7 cells compared to miRNA mimic-NC and mock treatments (Fig. $5 \mathrm{c})\left(F_{(3,8)}=14.14\right.$, $P=0.0015)$. All of the evidence illustrated that $T g$-DCExo-derived miR-155-5p contributed to M1 macrophage polarization.

\section{The miR-155-5p packed in Tg-DC-exo inhibits the multiplication of $T$. gondii RH tachyzoites}

Since increased production of proinflammatory factors inhibited T. gondii multiplication, and since we had identified that $\mathrm{Tg}$-DC-Exo-derived miR-155-5p upregulated the transcription of some proinflammatory cytokines (Figs. 3 and 5), we wondered whether the Tg-DC-Exoderived miR-155-5p inhibited T. gondii multiplication or not. We found that $\mathrm{Tg}$-DC-Exo treatment on RAW264.7 cells resulted in the inhibition of $T$. gondii replication in the RAW264.7 cells compared to that in DC-Exo treatment and nontreatment groups (Fig. $6 \mathrm{a})\left(F_{(2,6)}=14.74, P\right.$ $=0.028)$. We therefore assumed that the Tg-DC-Exo significantly enriched with miR-155-5p also had the same effect on $T$. gondii replication. To test this hypothesis, firstly, a CCK8 kit was used to examine the cell activity affected by miR-155-5p mimics or miR-155-5p inhibitors, and no significant differences were found between the RAW264.7 cell groups which were transfected or untransfected with these miRNAs (Additional file 4: Figure S3). Secondly, the T. gondii B1 gene copies (indicating the number of $T$. gondii tachyzoites) in the cells transfected with miR-155-5p mimics or miR-155-5p inhibitors were evaluated with qRT-PCR. The results showed us that the B1 gene copies were significantly lower in the RAW264.7 cells transfected with the miR-155-5p mimic than in the cells transfected with the miRNA mimic-NC and in the mock cells (Fig. $6 \mathrm{~b})\left(F_{(2,6)}=620.8, P=0.0004\right)$. On the contrary, the $\mathrm{B} 1$ gene copies were significantly higher in the RAW264.7 cells transfected with miR-155-5p inhibitors than in the cells transfected with the miRNA-NC inhibitor and the mock cells (Fig. $6 \mathrm{c})\left(F_{(2,6)}=15.22, P=\right.$ 


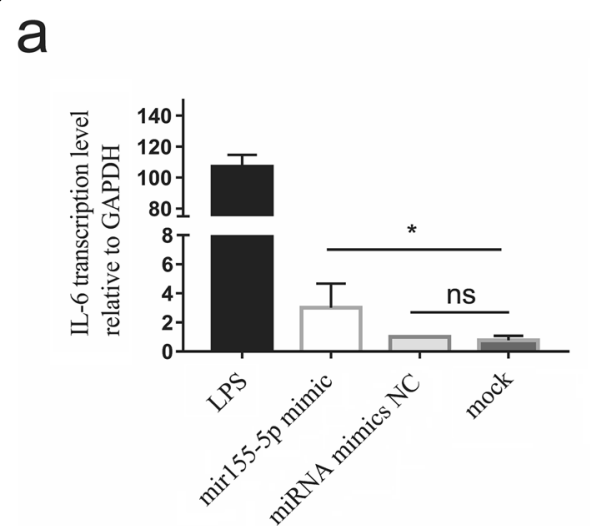

b
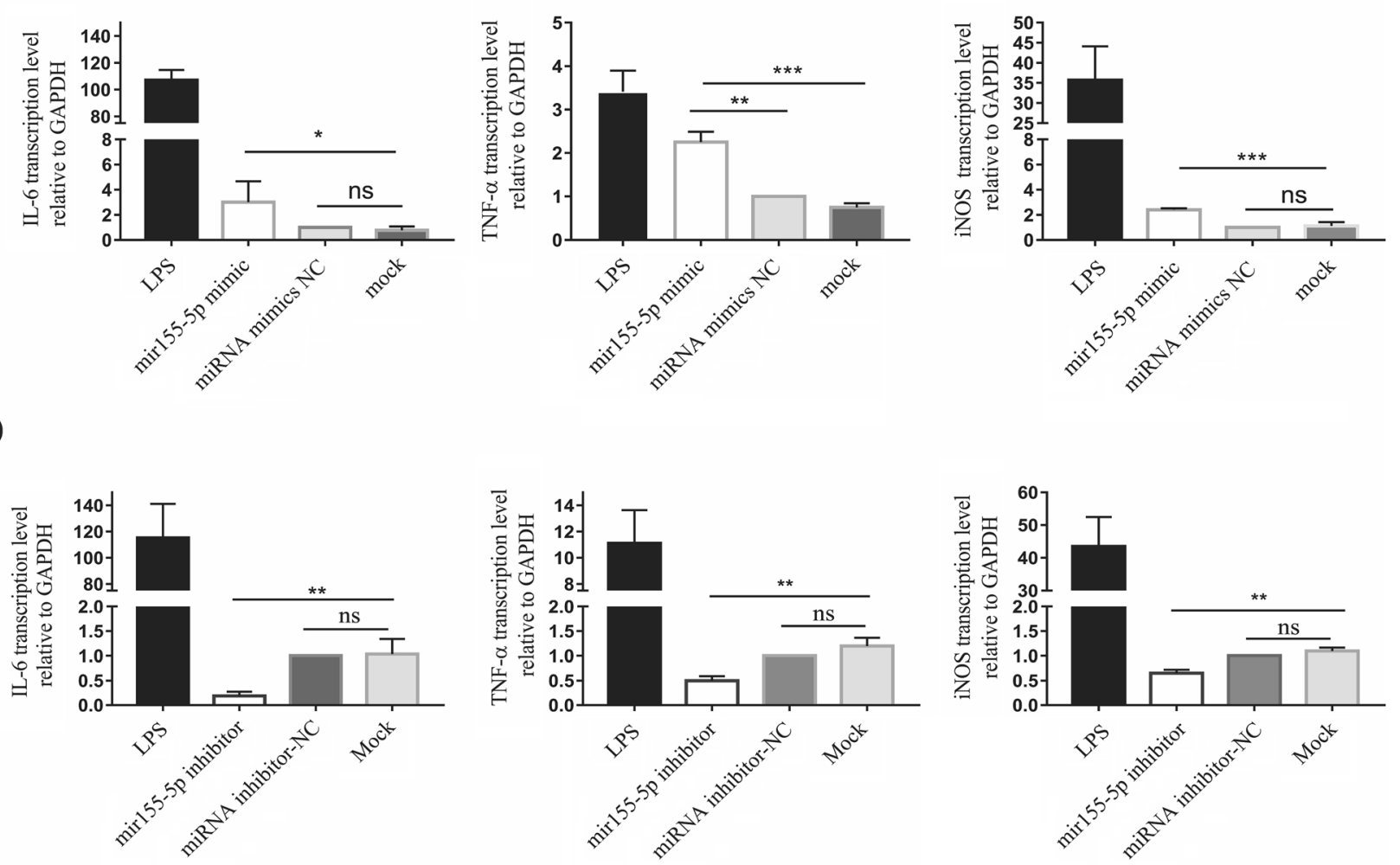

C

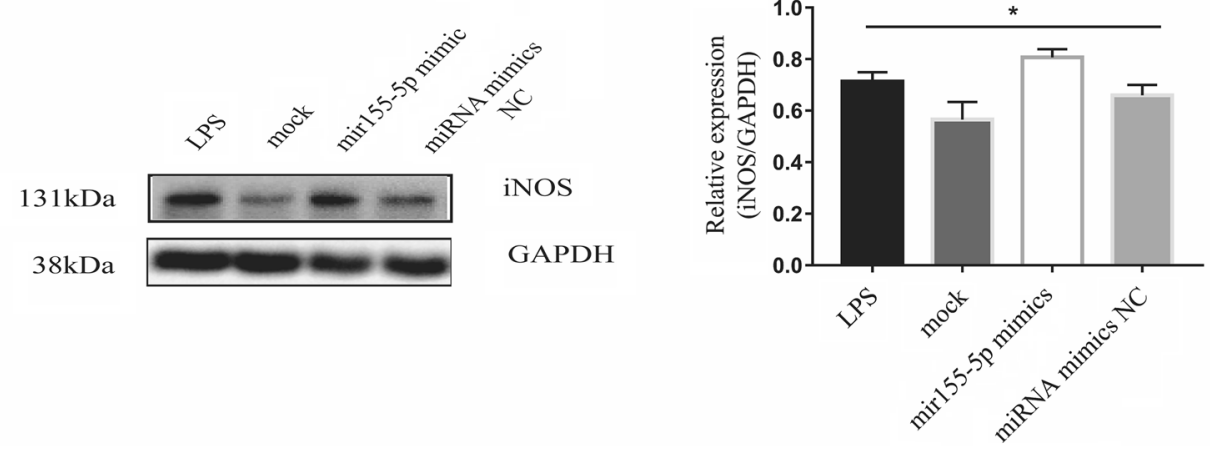

Fig. 5 Tg-DC-Exo-enriched miR-155-5p promotes macrophage M1 polarization. After the indicated treatment, the levels of mRNAs in RAW264.7 cells were quantified with qRT-PCR and are represented as the fold change relative to U6 (set to 1) for miR-155-5p or relative to GAPDH (set to 1) for IL-6, iNOS, and TNF-a. The relative transcription levels of IL-6, iNOS, and TNF-a in the miR-155-5p mimic-transfected RAW264.7 cells at $18 \mathrm{~h}$ post-transfection (a) and in the miR-155-5p inhibitor-transfected cells at $24 \mathrm{~h}$ post-transfection (b). Western blot assay for iNOS expression in the miR-155-5p mimic transfection group and the other groups as control at $48 \mathrm{~h}$ post-transfection (c, left). Densitometric quantitation of each band in c-left was applied using ImageJ software (c, right). The mimics control transfection, and mock cells were set as negative controls, and the lipopolysaccharide (LPS) treatment was set as the positive control. SPSS software was used for statistical analysis. One-way ANOVA was used for between-group comparisons, and Tukey's multiple-group test was used for multiple-group comparisons. Each experiment was carried out three times $\left({ }^{*} P<0.05,{ }^{* *} P<0.01\right.$ and $\left.{ }^{* * *} P<0.001\right)$

0.009). In brief, these results indicated that $\mathrm{Tg}$-DC-Exo treatment and the high level of miR-155-5p in RAW264.7 cells significantly inhibited the multiplication of $T$. gondii in these cells.
Tg-DC-exo-derived miR-155-5p targets socs 1 to activate the NF-KB signaling pathway in macrophages

To identify the target genes of miR-155-5p in RAW264.7, online bioinformatics tools (TargetScan and miRWalk) 

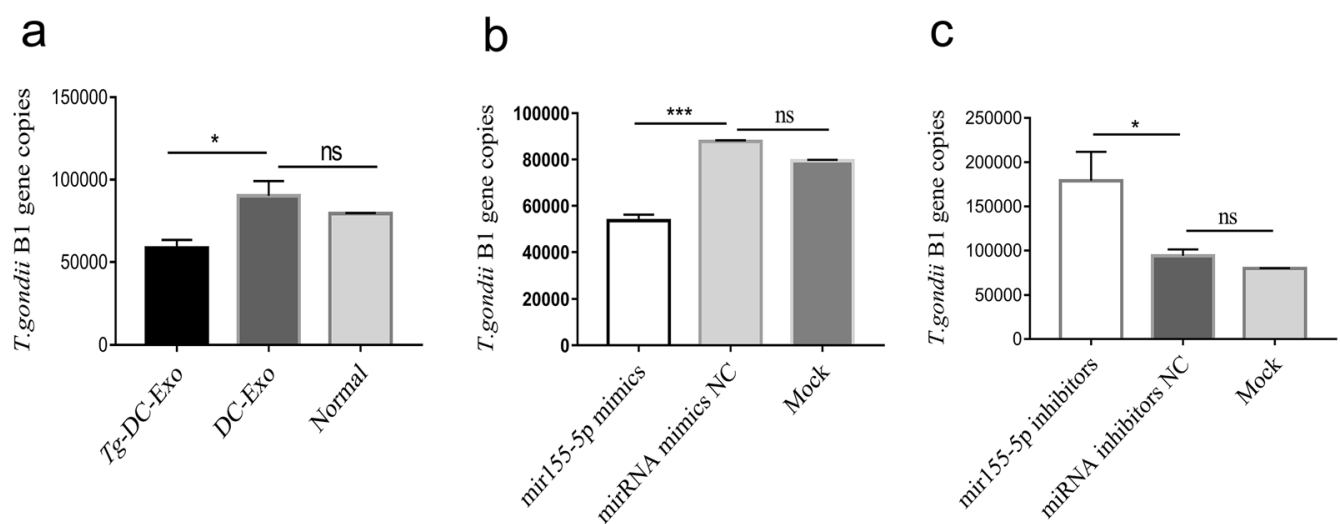

Fig. 6 Inhibited proliferation of T. gondii in the Tg-DC-Exo treatment and miR-155-5p transfection groups. The T. gondii B1 gene copies were quantified with qPCR. a The RAW264.7 cells were treated with $120 \mu \mathrm{g} / \mathrm{ml} \mathrm{Tg-DC-Exo} \mathrm{or} \mathrm{DC-Exo} \mathrm{for} 24 \mathrm{~h}$ and then infected with T. gondii for $24 \mathrm{~h}$. The RAW264.7 cells were transfected with miR-155-5p mimics (b) or miR-155-5p inhibitors (c) for $24 \mathrm{~h}$ and then infected with T. gondii for $24 \mathrm{~h}$; the mimic control transfection and mock cells were set as negative controls. SPSS software was used for statistical analysis. One-way ANOVA was used for between-group comparisons, and Tukey's multiple-group test was used for multiple-group comparisons. Each experiment was carried out three times $\left({ }^{*} P<0.05,{ }^{* *} P<0.001\right)$

were used to predict the potential target genes. Among the potential targets, the suppressor of cytokine signaling (socs1), which is involved in both immune modulation and cell cycle regulation, has been reported to be a negative feedback regulator of cytokines and to be involved in multiple signaling pathways [33]. Hence, we assumed that socs 1 was targeted by miR-155-5p and acted to promote macrophage M1 polarization. We found that the transcription and translation of socs 1 were significantly inhibited by miR-155-5p mimics compared to that in miRNA mimic-NC transfection and non-transfection groups (Fig. $7 \mathrm{a}\left(F_{(2,6)}=54.77, P=0.0004\right), \mathrm{b}\left(F_{(2,6)}=9.041, P=\right.$ 0.0136). Considering the fact that the activation of NF- $\mathrm{kB}$ plays a crucial role in M1 macrophage polarization and inhibition of T. gondii proliferation [34], we speculated that the miR-155-5p packed in $T g$-DC-Exo was transported to RAW264.7 cells and then targeted socs1 to activate the NF-kB signaling pathway. To test our hypothesis, socs1 was knocked down in RAW264.7 cells using small interfering RNAs targeting socs1 (si-socs1) (Fig. $7 \mathrm{c}\left(F_{(2,6)}=153.2, P=\right.$ $0.001), \mathrm{d}\left(F_{(2,6)}=31.26, P=0.005\right)$. We further found that miR-155-5p mimics and si-socs1 transfection promoted the phosphorylation of IKB $\alpha$ and p65 in RAW264.7 cells compared with the si-NC transfection and un-transfected groups (Fig. 7e, f) $(P<0.0001)$. IKB $\alpha$ and $\mathrm{p} 65$ phosphorylation represent the activation of NF- $\mathrm{kB}$ signaling; as a result, macrophage M1 polarization was subsequently induced. We also found that si-socs1 transfection to RAW264.7 cells did not affect the cell proliferation or viability (Additional file 5: Figure S4). Next, we investigated the role of SOCS1 in T. gondii RH proliferation in RAW264.7 cells by detecting T. gondii B1 gene copies in si-socs1 or si-NC transfected groups with qRT-PCR. No significant differences in T. gondii RH proliferation were found between the groups (Additional file 5: Figure S4c). Furthermore, when pretreated with IFN- $\gamma$, si-socs1 played a synergistic role in the inhibition of $T$. gondii proliferation (Fig. $7 \mathrm{~g})\left(F_{(3,8)}=105.2\right.$, $P<0.0001)$. Collectively, these results demonstrated that miR-155-5p targeted the socs 1 gene to activate the NF- $\mathrm{kB}$ signaling pathway and inhibited the proliferation of T. gondii in RAW264.7 cells.

\section{Discussion}

Host immune sensors recognize $T$. gondii infection and activate immune cells to produce proinflammatory cytokines against infection [35-37]. Here, we found that exosomes derived from dendritic cells could be ingested by RAW264.7 cells, and miR-155-5p was highly enriched in exosomes derived from dendritic cells infected with $T$. gondii ( $\mathrm{Tg}$-DC-Exo), but not in the exosomes from normal dendritic cells (DC-Exo). MiR-155-5p was found to target the socs1 gene to activate the NF- $\mathrm{kB}$ pathway, and subsequently inhibited T. gondii proliferation in RAW264.7 cells.

Exosomes, which are released by most cell types and pathogens and are involved in cell-to-cell communication, have been extensively studied in parasitic infection and disease progression [38]. It has been shown that abnormal cells produce more extracellular vesicles (EVs) than normal cells $[39,40]$. In our study, the exosomes derived from $T$. gondii-infected DC2.4 cells (Tg-DC-Exo) 


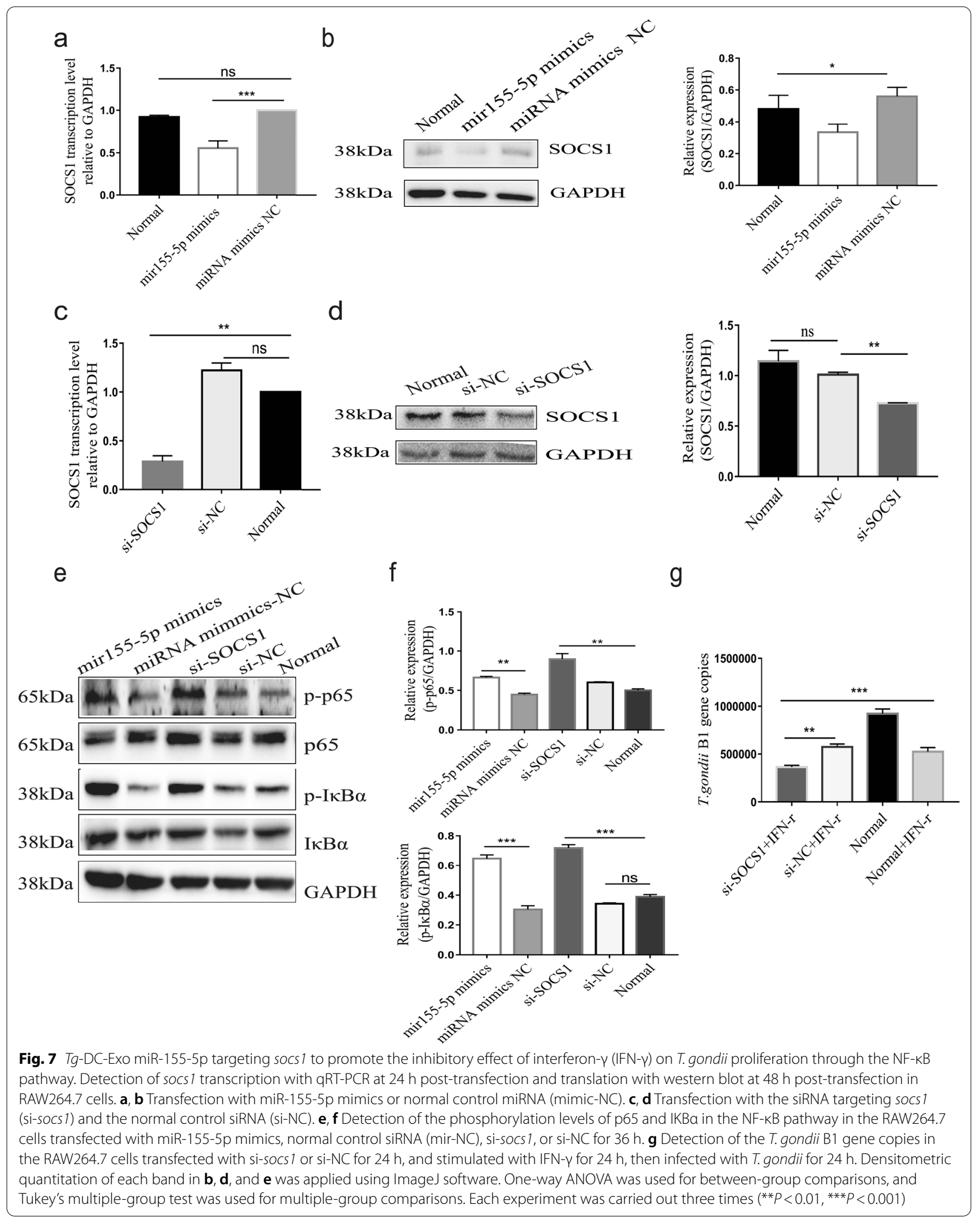


were found with higher particle concentration than those derived from normal DC2.4 cells (DC-Exo) (Fig. 1d), which is similar to the report by Wowk et al. [13].

During the phase of acute infection, the anti-Toxoplasma effect is mainly mediated by macrophage activation by IFN- $\gamma$ and cytotoxicity mediated by $\mathrm{CD} 8^{+} \mathrm{T}$ cells, which are attributed to the production of IFN- $\gamma$ and other inflammatory factors [41-43]. On the other hand, perforin was found to mediate cytotoxic activity of $\mathrm{CD}^{+} \mathrm{T}$ cells in the clearance of $T$. gondii cysts during chronic infection [44]. The RAW264.7 cell line has been used as a model for observing the intercellular transmission of infection signals between different types of immune cells in many reports [45-47]. In our study, we found that the intercellular communication between dendritic cells and macrophages could be realized through exosome transmission (Fig. 2). This could be a mechanism by which infection signals from infected cells are transmitted to uninfected cells.

Toxoplasma gondii infection altered the miRNA profiles of exosomes secreted from DC2.4 cells; for example, miR146a, let7k, and miR-155-5p were upregulated in DC2.4 cells after T. gondii infection [27]. It has been reported that miR-155 is sensitive to pathogen stimulation, abnormally expressed in activated dendritic cells, macrophages, $\mathrm{T}$ cells, and $\mathrm{B}$ cells, and induces a robust proinflammatory response in macrophages $[32,48]$. In our research, we found that RAW264.7 cells absorbed exosomes secreted by DC2.4 cells, and miR-155-5p was abundantly enriched in $T g$ DC-Exo and delivered to RAW264.7 cells via exosomes to activate the immune signaling pathways. Given the unique functions of miR-155 in the immune system, such as controlling inflammatory responses, regulating immune memory, and so on $[49,50]$, the regulation of immune responses by miR-155-5p in RAW 264.7 cells was further investigated.

We found that Tg-DC-Exo and miR-155-5p mimics boosted the transcription levels of IL-6, iNOS, and TNF- $\alpha$, which are macrophage M1-associated markers (Figs. 3 and 5). In T. gondii (RH) infection, dendritic cells transmitted immune signals to macrophages by secreting exosomes enriched with miR-155-5p. As a result, the macrophages were driven to M1 polarization and participated in the positive immune responses after receiving miR-155-5p. However, it has been reported that $T$. gondii (types I and III) direct infection drives the polarization of macrophages towards M2 [51]. It is possible that T. gondii (types I and III) ROP16 activates M2 macrophages by activating STAT6, which reduces the secretion of proinflammatory factors such as IL12 in the early infection stage, thus helping to reduce the host responses.

It is generally believed that M1 macrophages exert positive immunomodulatory effects and inhibit $T$. gondii multiplication by secreting proinflammatory cytokines TNF- $\alpha$ and IL- 6 and proinflammatory marker iNOS
$[43,52]$. Therefore, the inhibited proliferation of T. gondii was verified in the RAW264.7 cells transfected with miR-155-5p mimics (Fig. 6). We previously reported that the target genes of the significantly enriched miRNAs in $\mathrm{Tg}$-DC-Exo were mainly related to immunity and aggregated in NF- $\mathrm{KB}, \mathrm{MAPK}, \mathrm{P} 13 \mathrm{~K}-\mathrm{AKT}$, and the calcium signaling pathway [27]. It has also been reported that the immune functions of miR-155 fall mainly into the regulation of the socs1 gene [53]. We further verified that socs1 was the target gene of miR-155-5p through an experiment with miR-155-5p mimic transfection (Fig. 7a, b), and this result was consistent with that of the previous report by Ye et al. [54]. It has been shown that, as a negative feedback cytokine regulator, SOCS1 is involved in multiple immune-related signaling pathways [55-58]; on the other hand, as the NF- $\mathrm{kB}$ signaling pathway is crucial for inflammatory response regulation, it can be activated by a variety of proinflammatory factors [59]. In our studies, we found that the NF- $\mathrm{kB}$ signaling pathway was significantly activated after miR-155-5p mimics were transfected into RAW264.7 cells (Fig. 7e). However, the modulation of socs 1 by miR-155-5p may also affect cellular pathways other than the NF- $\mathrm{kB}$ pathway. Therefore, the function of the $T g$-DC-Exo-enriched miR-155-5p in anti-T. gondii infection remains to be further investigated.

Host IFN- $\gamma$ plays a crucial role in the control of T. gondii infection $[60,61]$. We found in our research that SOCS1, an effective inhibitor of the IFN- $\gamma$ pathway, showed an effect on the proliferation of T. gondii in RAW264.7 cells; when the RAW264.7 cells were treated with IFN- $\gamma$, the proliferation of $T$. gondii in the socs1 knockdown group was significantly more inhibited than in the normal control siRNA (si-NC) transfected cells and the normal control cells (both stimulated or not stimulated by IFN- $\gamma$ ) (Fig. 7g). This result implied an inhibitory role of SOCS1 in IFN- $\gamma$ anti-infection, which is consistent with the report that $T$. gondii induces host cell socs1 expression to block IFN- $\gamma$ signaling for immune evasion [62].

\section{Conclusions}

The exosomes secreted by DC2.4 cells infected with $T$. gondii (Tg-DC-Exo) transmitted T. gondii infection signals to RAW264.7 cells through the latter's exosome uptake. The enriched miR-155-5p in Tg-DC-Exo targeted the socs 1 gene to activate the NF-kB pathway and then to promote the transcription of inflammatory factors including TNF- $\alpha$, IL-6, and iNOS. As a result, T. gondii proliferation was inhibited in these RAW264.7 cells. This finding may provide new insight into intercellular communication for the transmission of infection signals between host cells, and may have implications for the role of exosomal miR-155-5p in anti-T. gondii infection. 


\section{Abbreviations}

T. gondii: Toxoplasma gondii; Exo: Exosomes; miRNA: MicroRNA; HFF: Human foreskin fibroblast; RAW264.7: Leukemia cells in mouse macrophage; FBS: Fetal bovine serum; TSG101: Tumor susceptibility gene 101; CD9: CD9 molecule; HSP70: Heat shock protein 70; CD81: CD81 molecule; LPS: Lipopolysaccharide; NF-KB: Nuclear factor kappa B; CCK8: Cell Counting Kit-8; iNOS: Inducible nitric oxide synthase; TNF-a: Tumor necrosis factor alpha; IL-6: Interleukin-6; SOCS1: Suppressor of cytokine signaling 1.

\section{Supplementary Information}

The online version contains supplementary material available at https://doi. org/10.1186/s13071-021-05003-x.

\section{Additional file 1: Table S1. Primers and siRNA, inhibitors, mimics} sequences list.

Additional file 2: Figure S1. Detection of miR-155-5p level and the cell proliferation in differently treated immune cells. a Detection of the miR155-5p level in the indicated cells at $24 \mathrm{~h}$ post-transfection. Left: RAW264.7 cells of normal, miR-155-5p mimics transfected, miRNA-mimic-NC transfected, miR-155-5p inhibitor transfected, miRNA-inhibitor-NC transfected, and mock. Right: DC2.4 cells of normal, miR-155-5p inhibitor transfected, and miRNA-inhibitor-NC transfected. b RAW264.7 cell proliferation was detected after transfection with miR-155-5p mimics or miR-155-5p inhibitors for 12, 24, 48, 72, and $96 \mathrm{~h}$, as indicated. The mimic control, inhibitor control, and normal cells were used as negative controls. One-way ANOVA was used for between-group comparisons, and Tukey's multiple-group test was used for multiple-group comparisons. Each experiment was carried out three times $\left({ }^{*} P<0.05,{ }^{* * *} P<0.0001\right)$

Additional file 3: Figure S2. Detection of IL-6, iNOS, and TNF-a transcription level in the RAW 264.7 cells treated with differently derived exosomes. The relative transcription levels of IL-6, iNOS, and TNF-a were detected in the RAW264.7 cells treated with the exosomes derived from the DC2.4 cells transfected with miR-155-5p inhibitor (miR-155-5p inhibitor-Exo) or miRNA inhibitor NC (miRNA inhibitor NC-Exo) at $24 \mathrm{~h}$ post-transfection.

Additional file 4: Figure S3. The cell viability detection of the RAW264.7 cells transfected with miR-155-5p mimics or inhibitors at $24 \mathrm{~h}$ post-transfection.

Additional file 5: Figure S4. Detection of the cell proliferation and viability of the RAW264.7 cells after different treatment. a RAW264.7 cell proliferation was detected after transfection with si-socs 1 , and si-NC for $12,24,48,72$, and 96 h. $\mathbf{b}$ The cell viability detection of the RAW264.7 cells transfected with si-socs 1, and si-NC for 24 h. c Detection of the T. gondii B1 gene copies in the RAW267.4 cells transfected with si-socs 1 or si-NC for $24 \mathrm{~h}$, then infected with T. gondii for $24 \mathrm{~h}$.

\section{Acknowledgements}

The authors are grateful to the participants in this study and the anonymous reviewers and editors for their comments and valuable inputs.

\section{Authors' contributions}

Conceptualization, data analysis, and validation: DJ, HJP. Funding acquisition: HJP. Investigation: DJ, SW, DL. Methodology: DJ, LX, GX. Project administration, resources and supervision: HP. Writing: DJ (original draft, and revision), HP (review, editing, and revision). All authors read and approved the final manuscript.

\section{Funding}

This research was supported by National Natural Science Foundation of China (81971954, 81772217), Science and Technology Planning Project of Guangdong Province (2018A050506038), Key project of Guangzhou science research (201904020011), and the Basic Research Project of Key Laboratory of Guangzhou (202102100001) to HJP.
Availability of data and materials

Not applicable.

\section{Declarations}

\section{Ethics approval and consent to participate}

Not applicable.

\section{Consent for publication}

Not applicable.

\section{Competing interests}

The authors declare no conflict of interest. The funders had no role in the design of the study; in the collection, analyses, or interpretation of data; in the writing of the manuscript; or in the decision to publish the results.

Received: 2 March 2021 Accepted: 8 September 2021

Published online: 06 January 2022

\section{References}

1. Montoya JG, Liesenfeld O. Toxoplasmosis. Lancet. 2004;363:1965-76.

2. Milne G, Webster JP, Walker M. Toxoplasma gondii: an underestimated threat? Trends Parasitol. 2020;36:959-69.

3. Batista SJ, Still KM, Johanson D, Thompson JA, O'Brien CA, Lukens JR. Gasdermin-D-dependent IL-1a release from microglia promotes protective immunity during chronic Toxoplasma gondii infection. Nat Commun. 2020;11:3687.

4. Nishiyama S, Pradipta A, Ma JS, Sasai M, Yamamoto M. T cell-derived interferon- $\gamma$ is required for host defense to Toxoplasma gondii. Parasitol Int. 2020;75:102049.

5. Ivanova DL, Mundhenke TM, Gigley JP. The IL-12- and IL-23-dependent NK cell response is essential for protective immunity against secondary Toxoplasma gondii infection. J Immunol. 2019;203:2944-58.

6. Essandoh K, LiY, Huo J, Fan GC. MiRNA-mediated macrophage polarization and its potential role in the regulation of inflammatory response. Shock. 2016;46:122-31.

7. Chen L, Christian DA, Kochanowsky JA, Phan AT, Clark JT, Wang S, et al. The Toxoplasma gondii virulence factor ROP16 acts in cis and trans, and suppresses T cell responses. J Exp Med. 2020;217:e20181757.

8. Wang JL, Bai MJ, Elsheikha HM, Liang QL, Li TT, Cao XZ, et al. Novel roles of dense granule protein 12 (GRA12) in Toxoplasma gondii infection. FASEB J. 2020;34:3165-78.

9. Mukhopadhyay D, Arranz-Solís D. Toxoplasma GRA15 and GRA24 are important activators of the host innate immune response in the absence of TLR11. PLoS Pathog. 2020;16:e1008586.

10. Pegtel DM, Gould SJ. Exosomes. Annu Rev Biochem. 2019;88:487-514

11. Kalluri R, LeBleu VS. The biology, function, and biomedical applications of exosomes. Science. 2020;367:eaau6977.

12. Pope SM, Lässer C. Toxoplasma gondii infection of fibroblasts causes the production of exosome-like vesicles containing a unique array of mRNA and miRNA transcripts compared to serum starvation. J Extracell Vesicles. 2013;2:22484

13. Wowk PF, Zardo ML, Miot HT, Goldenberg S, Carvalho PC, Mörking PA. Proteomic profiling of extracellular vesicles secreted from Toxoplasma gondii. Proteomics. 2017;17:1600477.

14. Li Y, Liu Y, Xiu F, Wang J, Cong H, He S, et al. Characterization of exosomes derived from Toxoplasma gondii and their functions in modulating immune responses. Int J Nanomed. 2018;13:467-77.

15. Silva VO, Maia MM, Torrecilhas AC, Taniwaki NN, Namiyama GM, Oliveira $\mathrm{KC}$, et al. Extracellular vesicles isolated from Toxoplasma gondii induce host immune response. Parasite Immunol. 2018;40:e12571.

16. Maia MM, da Cruz AB, Taniwaki NN, Namiyama GM, Gava R, Gomes AHS, et al. Immunization with extracellular vesicles excreted by Toxoplasma gondii confers protection in murine infection, activating cellular and humoral responses. Int J Parasitol. 2021;51:559-69. 
17. Beauvillain C, Juste MO, Dion S, Pierre J, Dimier-Poisson I. Exosomes are an effective vaccine against congenital toxoplasmosis in mice. Vaccine. 2009:27:1750-7.

18. Buck AH, Coakley G, Simbari F, McSorley HJ, Quintana JF, Le Bihan T, et al. Exosomes secreted by nematode parasites transfer small RNAs to mammalian cells and modulate innate immunity. Nat Commun. 2014;5:5488.

19. Samoil V, Dagenais M, Ganapathy V, Aldridge J, Glebov A, Jardim A, et al. Vesicle-based secretion in schistosomes: analysis of protein and microRNA (miRNA) content of exosome-like vesicles derived from Schistosoma mansoni. Sci Rep. 2018:8:3286

20. Długońska H, Gatkowska J. Exosomes in the context of Toxoplasma gondii-host communication. Ann Parasitol. 2016;62:169-74.

21. Xu Z, Zeng S, Gong Z, Yan Y. Exosome-based immunotherapy: a promising approach for cancer treatment. Mol Cancer. 2020;19:160.

22. Manca S, Upadhyaya B. Milk exosomes are bioavailable and distinct microRNA cargos have unique tissue distribution patterns. Sci Rep. 2018;8:11321.

23. Liu J, Zhu L, Wang J. Schistosoma japonicum extracellular vesicle miRNA cargo regulates host macrophage functions facilitating parasitism. PLoS Pathog. 2019;15:e1007817.

24. Dupont CD, Christian DA, Selleck EM, Pepper M, Leney-Greene M, Harms Pritchard $\mathrm{G}$, et al. Parasite fate and involvement of infected cells in the induction of $\mathrm{CD}^{+}$and $\mathrm{CD}^{+} \mathrm{T}$ cell responses to Toxoplasma gondii. PLoS Pathog. 2014;10:e1004047.

25. Poncet AF, Blanchard N, Marion S. Toxoplasma and dendritic cells: an intimate relationship that deserves further scrutiny. Trends Parasitol. 2019;35:870-86.

26. Delgado Betancourt E, Hamid B, Fabian BT, Klotz C, Hartmann S, Seeber F. From entry to early dissemination-Toxoplasma gondii's initial encounter with its host. Front Cell Infect Microbiol. 2019;9:46.

27. Li DL, Zou WH, Deng SQ, Peng HJ. Analysis of the differential exosomal miRNAs of DC2.4 dendritic cells induced by Toxoplasma gondii infection. Int J Mol Sci. 2019;20:5506.

28. Xu H, Ling M, Xue J, Dai X, Sun Q, Chen C, et al. Exosomal microRNA-21 derived from bronchial epithelial cells is involved in aberrant epitheliumfibroblast cross-talk in COPD induced by cigarette smoking. Theranostics. 2018;8:5419-33

29. Kong L, Jiang D, He C, Xia J, Wei H, Zhou L, et al. TgROP18 targets IL20RB for host-defense-related-STAT3 activation during Toxoplasma gondii infection. Parasit Vectors. 2020;13:400

30. Lin WC, Tsai CY, Huang JM, Wu SR, Chu LJ, Huang KY. Quantitative proteomic analysis and functional characterization of Acanthamoeba castellanii exosome-like vesicles. Parasit Vectors. 2019;12:467.

31. Wu SZ, Wei HX, Jiang D, Li SM, Zou WH, Peng HJ. Genome-wide CRISPR screen identifies host factors required by Toxoplasma gondii infection. Front Cell Infect Microbiol. 2019:9:460.

32. Elton TS, Selemon H, Elton SM, Parinandi NL. Regulation of the mir155 host gene in physiological and pathological processes. Gene. 2013;532:1-12.

33. Ilangumaran S, Bobbala D, Ramanathan S. SOCS1: regulator of T cells in autoimmunity and cancer. Curr Top Microbiol Immunol. 2017;410:159-89.

34. Mukhopadhyay D, Sangaré LO, Braun L, Hakimi MA. Toxoplasma GRA15 limits parasite growth in IFN- $\gamma$-activated fibroblasts through TRAF ubiquitin ligases. EMBO J. 2020;39:e103758.

35. Sasai M, Pradipta A, Yamamoto M. Host immune responses to Toxoplasma gondii. Int Immunol. 2018;30:113-9.

36. Lima TS, Lodoen MB. Mechanisms of human innate immune evasion by Toxoplasma gondii. Front Cell Infect Microbiol. 2019;9:103.

37. Suzuki Y. The immune system utilizes two distinct effector mechanisms of T cells depending on two different life cycle stages of a single pathogen, Toxoplasma gondii, to control its cerebral infection. Parasitol Int 2020:76:102030.

38. Lovo-Martins MI, Malvezi AD, Zanluqui NG, Lucchetti BFC, Tatakihara VLH, Mörking PA, et al. Extracellular vesicles shed by Trypanosoma cruzi potentiate infection and elicit lipid body formation and PGE(2) production in murine macrophages. Front Immunol. 2018;9:896.

39. Liu H, Sun $X$, Gong X, Wang G. Human umbilical cord mesenchymal stem cells derived exosomes exert antiapoptosis effect via activating PI3K/Akt/ mTOR pathway on H9C2 cells. J Cell Biochem. 2019;120:14455-64.

40. Zhang L, Yu D. Exosomes in cancer development, metastasis, and immunity. Biochim Biophys Acta Rev Cancer. 2019;1871:455-68.
41. Khan IA, Ely KH, Kasper LH. Antigen-specific CD8+ T cell clone protects against acute Toxoplasma gondii infection in mice. J Immunol. 1994;152:1856-60.

42. Shirahata T, Yamashita T, Ohta C, Goto H, Nakane A. CD8 ${ }^{+}$T lymphocytes are the major cell population involved in the early gamma interferon response and resistance to acute primary Toxoplasma gondii infection in mice. Microbiol Immunol. 1994;38:789-96.

43. Park J, Hunter CA. The role of macrophages in protective and pathological responses to Toxoplasma gondii. Parasite Immunol. 2020;42:e12712.

44. Suzuki Y, Wang X, Jortner BS, Payne L, Ni Y, Michie SA, et al. Removal of Toxoplasma gondii cysts from the brain by perforin-mediated activity of CD8 $^{+}$T cells. Am J Pathol. 2010;176:1607-13.

45. Tsitsiklis A, Bangs DJ, Robey EA. CD8(+) T cell responses to Toxoplasma gondii: lessons from a successful parasite. Trends Parasitol. 2019;35:887-98.

46. Kumar R, Loughland JR, Ng SS, Boyle MJ, Engwerda CR. The regulation of CD4(+) T cells during malaria. Immunol Rev. 2020;293:70-87.

47. Tiwari A, Hannah R, Lutshumba J, Ochiai E, Weiss LM, Suzuki Y. Penetration of CD8(+) cytotoxic T cells into large target, tissue cysts of Toxoplasma gondii, leads to its elimination. Am J Pathol. 2019;189:1594-607.

48. Croston TL, Lemons AR, Beezhold DH, Green BJ. MicroRNA regulation of host immune responses following fungal exposure. Front Immunol. 2018;9:170

49. Lim KH, Staudt LM. Toll-like receptor signaling. Cold Spring Harb Perspect Biol. 2013;5:a011247.

50. O'Connell RM, Taganov KD, Boldin MP, Cheng G, Baltimore D. MicroRNA-155 is induced during the macrophage inflammatory response. Proc Natl Acad Sci USA. 2007;104:1604-9.

51. Wang C, Cheng W, Yu Q, Xing T, Chen S, Liu L, et al. Toxoplasma Chinese 1 Strain of WH3 3 rop 16(I/III) /gra15(II) genetic background contributes to abnormal pregnant outcomes in murine model. Front Immunol. 2018;9:1222.

52. Yap GS, Sher A. Cell-mediated immunity to Toxoplasma gondii: initiation, regulation and effector function. Immunobiology. 1999;201:240-7.

53. Lu LF, Gasteiger G, Yu IS, Chaudhry A, Hsin JP, Lu Y, et al. A single miRNAmRNA interaction affects the immune response in a context- and celltype-specific manner. Immunity. 2015;43:52-64.

54. Ye J, Guo R, Shi Y, Qi F, Guo C, Yang L. mir-155 regulated inflammation response by the SOCS1-STAT3-PDCD4 axis in atherogenesis. Mediat Inflamm. 2016:2016:8060182.

55. Shi D, Li D, Wang Q, Kong X, Mei H, Shen Y, et al. Silencing SOCS1 in dendritic cells promote survival of mice with systemic Candida albicans infection via inducing Th1-cell differentiation. Immunol Lett. 2018;197:53-62.

56. He Q, Sun C, Lei W, Ma J. SOCS1 regulates apoptosis and inflammation by inhibiting IL-4 signaling in IL-1 $\beta$-stimulated human osteoarthritic chondrocytes. Biomed Res Int. 2017:2017:4601959.

57. Yoshimura A, Ito M, Chikuma S, Akanuma T, Nakatsukasa H. Negative regulation of cytokine signaling in immunity. Cold Spring Harb Perspect Biol. 2018;10:a028571.

58. Liang YB, Tang H, Chen ZB, Zeng LJ, Wu JG, Yang W, et al. Downregulated SOCS1 expression activates the JAK1/STAT1 pathway and promotes polarization of macrophages into M1 type. Mol Med Rep. 2017;16:6405-11.

59. Thoma A, Lightfoot AP. NF-kB and inflammatory cytokine signalling: role in skeletal muscle atrophy. Adv Exp Med Biol. 2018;1088:267-79.

60. Bando H, Lee Y, Sakaguchi N, Pradipta A, Sakamoto R, Tanaka S, et al. Toxoplasma effector GRA15-dependent suppression of IFN- $\gamma$-induced antiparasitic response in human neurons. Front Cell Infect Microbiol. 2019;9:140.

61. Liau NPD, Laktyushin A, Lucet IS, Murphy JM, Yao S, Whitlock E, et al. The molecular basis of JAK/STAT inhibition by SOCS1. Nat Commun. 2018;9:1558.

62. Stutz A, Kessler H, Kaschel ME, Meissner M, Dalpke AH. Cell invasion and strain dependent induction of suppressor of cytokine signaling-1 by Toxoplasma gondii. Immunobiology. 2012;217:28-36.

\section{Publisher's Note}

Springer Nature remains neutral with regard to jurisdictional claims in published maps and institutional affiliations. 